\title{
Case Report \\ Successful Pulmonary Endarterectomy in a Patient with Klinefelter Syndrome
}

\author{
E. Wierda, ${ }^{1}$ H. J. Reesink, ${ }^{2,3,4}$ H. Bruining, ${ }^{5}$ O. M. van Delden, ${ }^{6}$ J. J. Kloek, ${ }^{7}$ and P. Bresser ${ }^{3,4,7}$ \\ ${ }^{1}$ Departments of Cardiology, Onze Lieve Vrouwe Gasthuis, 1090 HM Amsterdam, The Netherlands \\ ${ }^{2}$ Department of Respiratory Medicine, St. Antonius Ziekenhuis, 3430 EM Nieuwegein, The Netherlands \\ ${ }^{3}$ Department of Pulmonology, Academic Medical Center of the University of Amsterdam, 1105 AZ Amsterdam, The Netherlands \\ ${ }^{4}$ Department of Respiratory Medicine, Onze Lieve Vrouwe Gasthuis, 1090 HM Amsterdam, The Netherlands \\ ${ }^{5}$ Department of Psychiatry, Rudolf Magnus Institute of Neuroscience, 3584 CG Utrecht, The Netherlands \\ ${ }^{6}$ Department of Radiology, Academic Medical Center of the University of Amsterdam, 1105 AZ Amsterdam, The Netherlands \\ ${ }^{7}$ Department of Cardiothoracic Surgery, Academic Medical Center of the University of Amsterdam, Amsterdam, The Netherlands
}

Correspondence should be addressed to E. Wierda, e.wierda@olvg.nl

Received 4 November 2012; Accepted 26 November 2012

Academic Editors: L. Borderías, T. Kawashima, T. Kelesidis, M. Kreuter, J. Murchison, and M. Takao

Copyright ( $) 2012$ E. Wierda et al. This is an open access article distributed under the Creative Commons Attribution License, which permits unrestricted use, distribution, and reproduction in any medium, provided the original work is properly cited.

Klinefelter syndrome (KS) is a frequent genetic disorder due to one or more supernumerary X chromosomes. KS is associated with an increased risk for venous thromboembolic events like deep venous thrombosis and pulmonary embolism. This paper describes a 37-year-old male patient with KS referred to our tertiary center with chronic thromboembolic pulmonary hypertension, and who was successfully treated by pulmonary endarterectomy.

\section{Introduction}

Klinefelter syndrome (KS; 47, XXY or higher aneuploidies) is a complex genetic disorder with highly variable endocrinological, metabolic, morphological, and neurobehavioral manifestations of altered X-chromosomal gene expression. Recent studies estimate the prevalence of KS $1: 640[1,2]$, which makes it the most prevalent aneuploidy in males and also the most frequent cause of male infertility. KS is also associated with an increased risk for venous thromboembolic events (VTEs) like deep venous thrombosis (DVT) and pulmonary embolism (PE) [3]. Although the underlying mechanism is incompletely understood, it is thought to be related to a hypogonadism syndrome leading to an increased synthesis and activity of plasminogen activator inhibitor-1 (PAI-1) and thus a reduced fibrinolytic activity [3]. It might be hypothesized that patients with KS are also at higher risk to develop chronic thromboembolism and chronic thromboembolic pulmonary hypertension (CTEPH) [4]; however, no such case was reported before. Here, we report a case of a 37-year-old KS patient who suffered from CTEPH, and who was successfully treated by pulmonary endarterectomy.

\section{Case Report}

A 37-year-old male was referred to the CTEPH center of the Academic Medical Center of the University of Amsterdam for the analysis of suspected CTEPH. At the age of 30, he was diagnosed with KS by genetic counseling (karyotype 47 , $\mathrm{XXY}$ ). One year later, following a high energetic trauma complicated with osteomyelitis of the right femur, he presented with acute onset dyspnea. By computed tomographic (CT) pulmonary angiography, acute bilateral PE was diagnosed as sequelae of a DVT of the right leg. The patient's family history was negative for VTE. Anticoagulant treatment was instituted with vitamin $\mathrm{K}$ antagonists for total duration of six months, whereupon he recovered promptly.

Six years later, however, he started to suffer from slow onset dyspnea on exertion. Perfusion scintigraphy showed multiple segmental and subsegmental defects, consistent with possible pulmonary embolism. Since anticoagulant treatment for six months did not improve his complaints, he was referred to our hospital. At referral, the patient was in no respiratory distress at rest, with a peripheral oxygen saturation of $99 \%$. He was mildly retarded and obese (body 


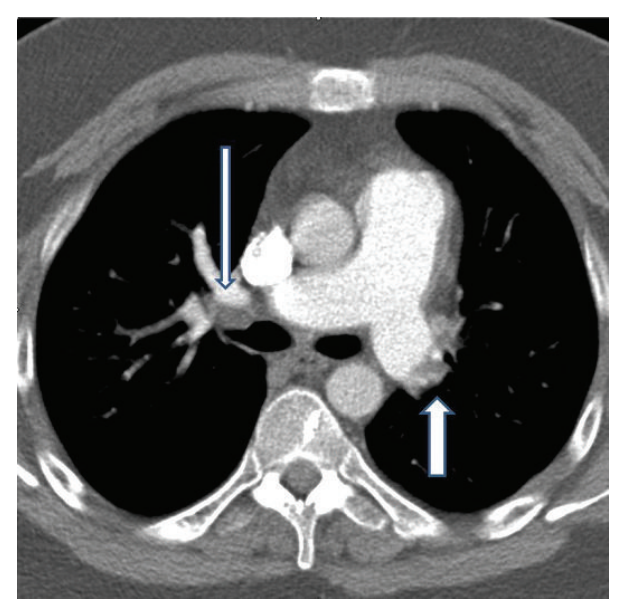

Figure 1: Computed tomography angiogram showing chronic thromboembolic clots in the central left and right pulmonary arteries (arrows).

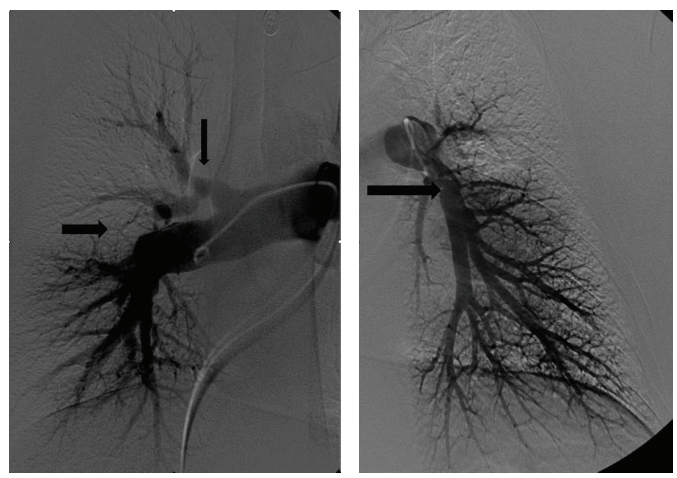

FIGURE 2: Distraction pulmonary angiogram of the right and left pulmonary artery demonstrating a web and acute stops in the right upper and lower lobe arteries as well as in the left lower lobe artery (arrows).

mass index 31.7), had a thickened neck, and a widened forehead with little hair growth. Systemic blood pressure was 120/80 mmHg. Cardiac and pulmonary examinations were normal, except for a split second heart tone. No peripheral oedema was observed. Laboratory tests were within normal range; NT pro-BNP:120 micrograms $/ \mathrm{mL}(N<200 \mathrm{pmol} / \mathrm{l}$, [5]). No coagulation abnormalities were detected, except for Factor VIII which was slightly elevated $211 \%(N<$ $150 \%)$. CT angiography demonstrated large, organized thrombi in the left main pulmonary artery, as well as in the right upper lobe multiple webs (Figure 1). Pulmonary angiography confirmed the diagnosis of proximal CTEPH with multiple webs on both sides and a central pouch in the left main pulmonary artery with diminished perfusion to the left upper lobe (Figure 2). Exercise capacity was decreased; the distance walked in the 6-minute walk test (6-MWD) was 480 meters (predicted value of 658 meters [6]). Echocardiography showed a dilated and hypertrophied right ventricle; systolic right ventricular function was normal (TAPSE $2.4 \mathrm{~cm}$ ). Estimated systolic pulmonary

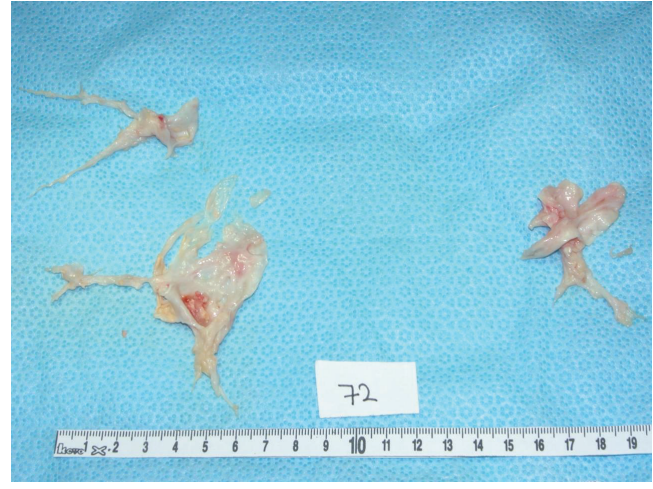

FIGURE 3: Chronic thromboembolic material obtained by pulmonary endarterectomy demonstrating central pouches from the right and left main pulmonary artery.

artery pressure (SPAP) was $65 \mathrm{mmHg}(N<40 \mathrm{mmHg})$. Left ventricular dimensions and function were normal. Right heart catheterisation demonstrated a pulmonary artery pressure of $59 / 29 \mathrm{mmHg}$, mean PAP of $43 \mathrm{mmHg}(N<$ $25 \mathrm{mmHg}$ ), cardiac output of $6.0 \mathrm{~L} / \mathrm{min}$, pulmonary wedge pressure of $6 \mathrm{mmHg}$, mean right atrial pressure of $11 \mathrm{mmHg}$, and the calculated pulmonary vascular resistance (PVR) of 493 dynes $\cdot \mathrm{s} \cdot \mathrm{cm}^{-5}$.

The patient was diagnosed with proximal CTEPH. His functional impairment was classified as New York Heart Association (NYHA) III/IV; that is marked limitation in activity due to symptoms, even during less-than-ordinary activity. Without treatment, he had an estimated 5-year survival of less than $30 \%$ [7]. A multidisciplinary team consisting of a pulmonologist, a radiologist, and a thoracic surgeon considered the patient eligible for pulmonary endarterectomy (PEA). A PEA was performed, as previously described, under deep hypothermia and cardiac arrest [8]. The organized thrombi were successfully removed (Figure 3 ). Two days after surgery, mean PAP was $22 \mathrm{mmHg}$. The patient recovered promptly without any complication and could be dismissed after 2 weeks. At 1-year followup, the patient was in NYHA functional class I/IV (no symptoms, and no limitation in ordinary physical activity); subjectively, his exercise tolerance had fully normalised, and the 6-MWD had increased to 580 meters. Echocardiography at one year after surgery showed a normalized diameter of the right ventricle and an estimated systolic PAP of $27 \mathrm{mmHg}$. At 5year followup, now, the patient is still in NYHA functional class I/IV, and he walked 630 meters in the 6-MWT.

\section{Discussion}

KS is associated with substantial morbidity [9] and increased mortality [10] with an increased relative risk of death due to diabetes, cardiovascular, respiratory, and gastrointestinal disorders [11]. KS is caused by chromosomal aneuploidy, in $80 \%$ of cases due to chromosome aberration $47 \mathrm{XXY}$ [12]. The prototypic KS man has traditionally been described as tall, with small testes, and decreased verbal intelligence, but 
the clinical picture may range variably [9]. Here, we reported a patient with KS diagnosed at the age of 30 , who developed symptomatic CTEPH six years after an acute pulmonary embolism.

CTEPH results from incomplete resolution of the vascular obstruction caused by pulmonary thromboembolism [13]. The incidence of CTEPH after acute pulmonary embolism is unknown but may be as high as $4 \%$ in patients after a first acute pulmonary embolism [13]. If left untreated, prognosis is poor and survival is related to the degree of pulmonary hypertension. Five-year survival in patients with a mean PAP above $30 \mathrm{mmHg}$ is $30 \%$, whereas patients with a mean PAP above $50 \mathrm{mmHg}$ have a 5 -year survival of only $10 \%$ [7]. Although specific pulmonary antihypertensive medication is currently available (such as endothelin-1 antagonists, phosfodiesterase- 5 inhibitors, and prostanoids $[14,15])$, PEA represents the therapy of choice for patients with surgically accessible thrombi $[8,16-18]$. After surgery, most patients experience a substantial hemodynamic and functional improvement and have an excellent long-term survival $[8,16,17,19]$.

CTEPH manifested in this patient six years after the documented acute pulmonary embolism. Moreover, he had been fully asymptomatic for several years. Therefore, it is highly unlikely that it has been merely the consequence of this episode. Pengo et al. showed that CTEPH manifests itself within 2 years after an episode of pulmonary embolism [13]. Retrospectively, he did not recall any other acute episode. So, whether the development of CTEPH in our patient was caused by recurrent VTE, in situ thrombosis, or both remains unknown.

Thromboembolic disease is frequently observed in KS [3, 12]; however, the increased incidence of VTE is incompletely understood yet. The hypogonadism syndrome leads to an increased synthesis and activity of PAI-1 [20]. Plasma levels of PAI-1 are inversely correlated to the testosterone levels, and positively to the extent of obesity, as expressed by the BMI [21]. However, it is believed by most authors that additional thrombophilic conditions, such as Protein C deficiency [22], Factor V Leiden, or Factor II mutation, are mandatory to cause severe VTE $[3,23,24]$. Obesity that is also frequently observed in KS patients may serve as an additional independent risk factor for VTE in these patients [25]. In the present case, osteomyelitis in the absence of hormonal substitutional therapy may have triggered the initial DVT. Also, at referral to our hospital, Factor VIII levels were mildly elevated. Factor VIII is a well-recognised risk factor for single [26] and recurrent VTE [27]. Moreover, elevated levels of Factor VIII have been described in CTEPH patients [28].

As in VTE, elevation of PAI-1 activity is also considered to play a role in the pathogenesis of (postthrombotic) leg ulceration observed in KS patients [29, 30]. Postthrombotic venous ulceration is observed in up to $13 \%$ of KS patients [31]; in fact, this may trigger suspicion on KS [32]. In addition, the frequency of pulmonary embolism in KS is likely to be 5-17 times higher [3], and also a higher incidence of chronic thromboembolism in KS may be expected. This is important as most men with KS (64\%) remain undiagnosed due to the highly variable and heterogeneous clinical presentation and insufficient professional awareness of this highly frequent syndrome [33]. Early diagnosis of KS might reduce the risk for VTE and timely androgen treatment will exert a favorable profibrinolytic effect [12]. Thus, both from the viewpoint of early detection as well as for early intervention, the association of KS with thromboembolic events needs to be more firmly acknowledged.

In conclusion, future studies are warranted to unravel the pathogenesis of VTE and the incidence of chronic thromboembolism in KS patients. However, given the increased incidence of VTE, in KS patients presenting with dyspnoea with or without a previous history of VTE, CTEPH must be considered. CTEPH is a life-threatening yet potentially curable form of pulmonary hypertension if diagnosed early in the course of the disease [16].

\section{Abbreviations}

KS: $\quad$ Klinefelter syndrome

VTEs: Venous thromboembolic events

DVT: Deep venous thrombosis

PE: $\quad$ Pulmonary embolism

CTEPH: Chronic thromboembolic pulmonary hypertension (CTEPH)

CT: Computed tomographic

NYHA: New York Heart Association

PEA: Pulmonary endarterectomy

PVR: Pulmonary vascular resistance

6-MWT: 6-minute walking test.

\section{Conflict of Interests}

The authors declare that they have no any conflict of interests.

\section{References}

[1] A. S. Herlihy, J. L. Halliday, M. L. Cock, and R. I. McLachlan, "The prevalence and diagnosis rates of Klinefelter syndrome: an Australian comparison," Medical Journal of Australia, vol. 194, no. 1, pp. 24-28, 2011.

[2] J. K. Morris, E. Alberman, C. Scott, and P. Jacobs, "Is the prevalence of Klinefelter syndrome increasing?" European Journal of Human Genetics, vol. 16, no. 2, pp. 163-170, 2008.

[3] W. A. Campbell and W. H. Price, "Venous thromboembolic disease in Klinefelter's syndrome," Clinical Genetics, vol. 19, no. 4, pp. 275-280, 1981.

[4] D. Bonderman, H. Wilkens, S. Wakounig et al., "Risk factors for chronic thromboembolic pulmonary hypertension," European Respiratory Journal, vol. 33, no. 2, pp. 325-331, 2009.

[5] J. L. Januzzi Jr., C. A. Camargo, S. Anwaruddin et al., “The Nterminal Pro-BNP investigation of dyspnea in the emergency department (PRIDE) study," American Journal of Cardiology, vol. 95, no. 8, pp. 948-954, 2005.

[6] S. Jenkins, N. Cecins, B. Camarri, C. Williams, P. Thompson, and P. Eastwood, "Regression equations to predict 6-minute walk distance in middle-aged and elderly adults," Physiotherapy Theory and Practice, vol. 25, no. 7, pp. 516-522, 2009. 
[7] M. Riedel, V. Stanek, J. Widimsky, and I. Prerovsky, "Longterm follow-up of patients with pulmonary thromboembolism. Late prognosis and evolution of hemodynamic and respiratory data," Chest, vol. 81, no. 2, pp. 151-158, 1982.

[8] H. J. Reesink, J. T. Marcus, I. I. Tulevski et al., "Reverse right ventricular remodeling after pulmonary endarterectomy in patients with chronic thromboembolic pulmonary hypertension: utility of magnetic resonance imaging to demonstrate restoration of the right ventricle," Journal of Thoracic and Cardiovascular Surgery, vol. 133, no. 1, pp. 58-64, 2007.

[9] A. Bojesen, S. Juul, N. H. Birkebæk, and C. H. Gravholt, "Morbidity in Klinefelter syndrome: a Danish register study based on hospital discharge diagnoses," Journal of Clinical Endocrinology and Metabolism, vol. 91, no. 4, pp. 1254-1260, 2006.

[10] A. J. Swerdlow, C. D. Higgins, M. J. Schoemaker, A. F. Wright, and P. A. Jacobs, "Mortality in patients with Klinefelter syndrome in britain: a cohort study," Journal of Clinical Endocrinology and Metabolism, vol. 90, no. 12, pp. 6516-6522, 2005.

[11] A. J. Swerdlow, C. Hermon, P. A. Jacobs et al., "Mortality and cancer incidence in persons with numerical sex chromosome abnormalities: a cohort study," Annals of Human Genetics, vol. 65, no. 2, pp. 177-188, 2001.

[12] F. Lanfranco, A. Kamischke, M. Zitzmann, and P. E. Nieschlag, "Klinefelter's syndrome," The Lancet, vol. 364, no. 9430, pp. 273-283, 2004.

[13] V. Pengo, A. W. A. Lensing, M. H. Prins et al., "Incidence of chronic thromboembolic pulmonary hypertension after pulmonary embolism," The New England Journal of Medicine, vol. 350, no. 22, pp. 2257-2323, 2004.

[14] H. J. Reesink, S. Surie, J. J. Kloek et al., "Bosentan as a bridge to pulmonary endarterectomy for chronic thromboembolic pulmonary hypertension," Journal of Thoracic and Cardiovascular Surgery, vol. 139, no. 1, pp. 85-91, 2010.

[15] P. Bresser and S. Surie, "Medical therapy for chronic thromboembolic pulmonary hypertension," Multidisciplinary Respiratory Medicine, vol. 3, no. 6, pp. 434-439, 2008.

[16] C. J. Archibald, W. R. Auger, P. F. Fedullo et al., "Long-term outcome after pulmonary thromboendarterectomy," American Journal of Respiratory and Critical Care Medicine, vol. 160, no. 2, pp. 523-528, 1999.

[17] S. W. Jamieson, D. P. Kapelanski, N. Sakakibara et al., "Pulmonary endarterectomy: experience and lessons learned in 1,500 Cases," Annals of Thoracic Surgery, vol. 76, no. 5, pp. 1457-1464, 2003.

[18] G. Piazza and S. Z. Goldhaber, "Chronic thromboembolic pulmonary hypertension," The New England Journal of Medicine, vol. 364, no. 4, pp. 351-360, 2011.

[19] H. J. Reesink, M. N. van der Plas, N. E. Verhey, R. P. van Steenwijk, J. J. Kloek, and P. Bresser, "Six-minute walk distance as parameter of functional outcome after pulmonary endarterectomy for chronic thromboembolic pulmonary hypertension," Journal of Thoracic and Cardiovascular Surgery, vol. 133, no. 2, pp. 510-516, 2007.

[20] M. Lapecorella, R. Marino, G. De Pergola, F. A. Scaraggi, V. Speciale, and V. De Mitrio, "Severe venous thromboembolism in a young man with Klinefelter's syndrome and heterozygosis for both G20210A prothrombin and factor V Leiden mutations," Blood Coagulation and Fibrinolysis, vol. 14, no. 1, pp. 95-98, 2003.

[21] P. Caron, A. Bennet, R. Camare, J. P. Louvet, B. Boneu, and P. Sie, "Plasminogen activator inhibitor in plasma is related to testosterone in men," Metabolism, vol. 38, no. 10, pp. 10101015, 1989.

[22] L. R. Ranganath, L. Jones, A. G. Lim, S. R. Gould, and P. F. Goddard, "Thrombophilia in a man with long-standing hypogonadism," Postgraduate Medical Journal, vol. 73, no. 865, pp. 761-763, 1997.

[23] R. Kasten, G. Pfirrmann, and V. Voigtländer, "Klinefelter's syndrome associated with mixed connective tissue disease (Sharp's syndrome) and thrombophilia with postthrombotic syndrome," Journal of the German Society of Dermatology, vol. 3, no. 8, pp. 623-626, 2005.

[24] G. R. Mount and J. D. Roebuck, "Antiphospholipid syndrome in a 21-year-old with klinefelter syndrome," Journal of Clinical Rheumatology, vol. 15, no. 1, pp. 27-28, 2009.

[25] S. Eichinger, G. Hron, C. Bialonczyk et al., "Overweight, obesity, and the risk of recurrent venous thromboembolism," Archives of Internal Medicine, vol. 168, no. 15, pp. 1678-1683, 2008.

[26] J. O’Donnell, E. G. D. Tuddenham, R. Manning, G. KemballCook, D. Johnson, and M. Laffan, "High prevalence of elevated factor VIII levels in patients referred for thrombophilia screening: role of increased synthesis and relationship to the acute phase reaction," Thrombosis and Haemostasis, vol. 77, no. 5, pp. 825-828, 1997.

[27] P. A. Kyrle, E. Minar, M. Hirschl et al., "High plasma levels of factor VIII and the risk of recurrent venous thromboembolism," The New England Journal of Medicine, vol. 343, no. 7, pp. 457-462, 2000.

[28] D. Bonderman, P. L. Turecek, J. Jakowitsch et al., "High prevalence of elevated clotting factor VIII in chronic thromboembolic pulmonary hypertension," Thrombosis and Haemostasis, vol. 90, no. 3, pp. 372-376, 2003.

[29] T. M. Zollner, J. C. J. M. Veraart, M. Wolter et al., "Leg ulcers in Klinefelter's syndrome-further evidence for an involvement of plasminogen activator inhibitor-1," British Journal of Dermatology, vol. 136, no. 3, pp. 341-344, 1997.

[30] E. J. Higgins, M. J. Tidman, G. F. Savidge, J. Beard, and D. M. MacDonald, "Platelet hyperaggregability in two patients with Klinefelter's syndrome complicated by leg ulcers," British Journal of Dermatology, vol. 120, no. 2, p. 322, 1989.

[31] W. A. Campbell, M. S. Newton, and W. H. Price, "Hypostatic leg ulceration and Klinefelter's syndrome," Journal of Mental Deficiency Research, vol. 24, no. 2, pp. 115-117, 1980.

[32] C. Spier, N. H. Shear, and R. S. Lester, "Recurrent leg ulcerations as the initial clinical manifestation of Klinefelter's syndrome," Archives of Dermatology, vol. 131, no. 2, p. 230, 1995.

[33] L. Abramsky and J. Chapple, “47,XXY (Klinefelter syndrome) and 47,XYY: estimated rates of and indication for postnatal diagnosis with implications for prenatal counselling," Prenatal Diagnosis, vol. 17, pp. 363-368, 1997. 


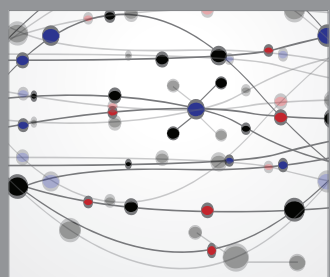

The Scientific World Journal
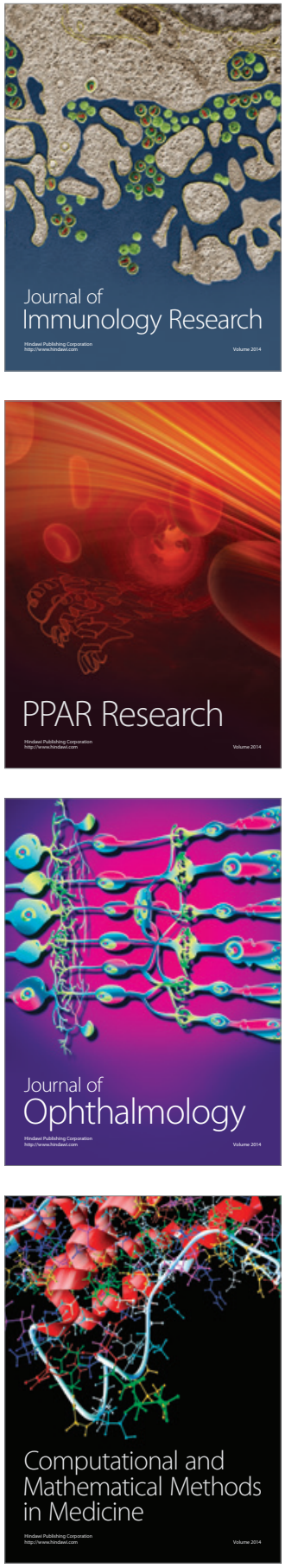

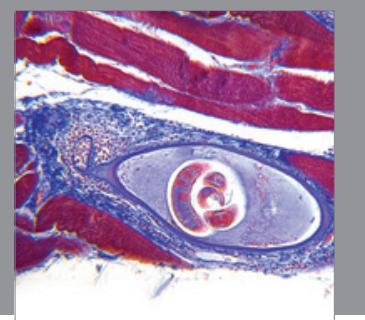

Gastroenterology

Research and Practice
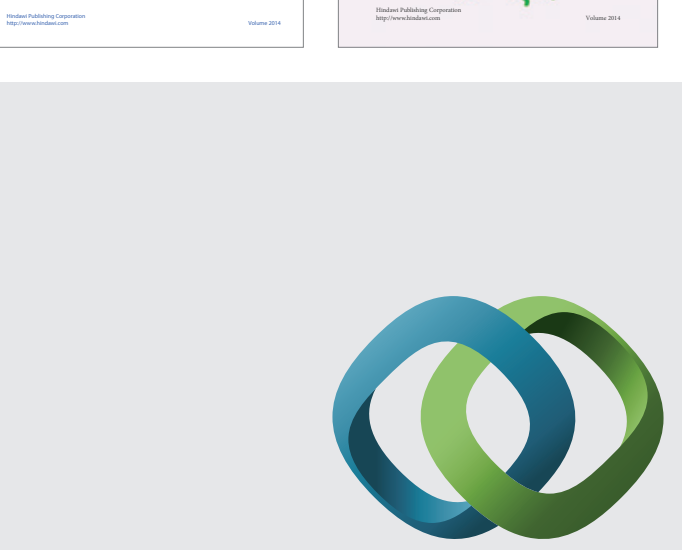

\section{Hindawi}

Submit your manuscripts at

http://www.hindawi.com
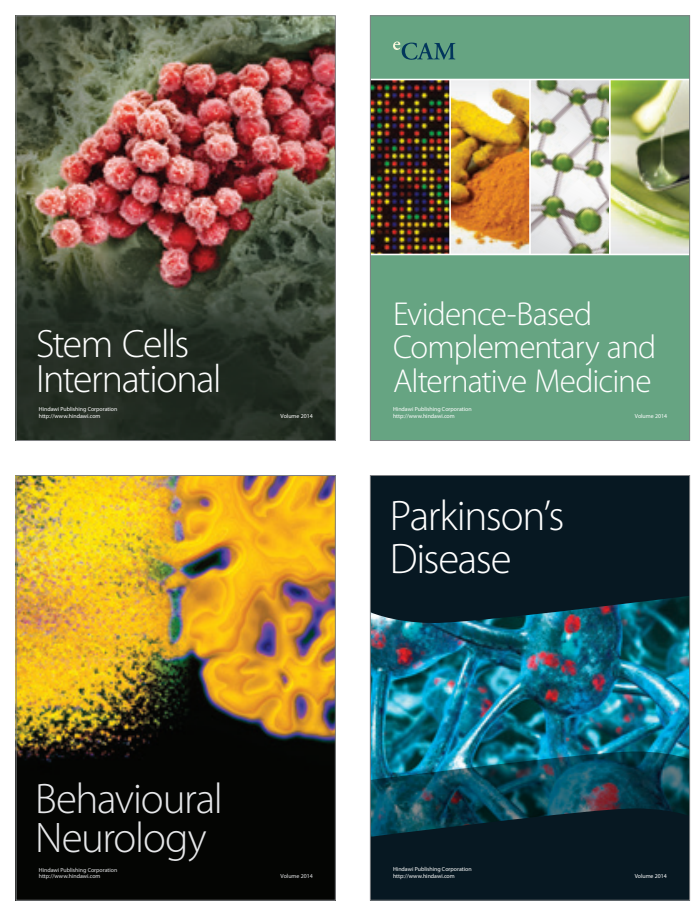

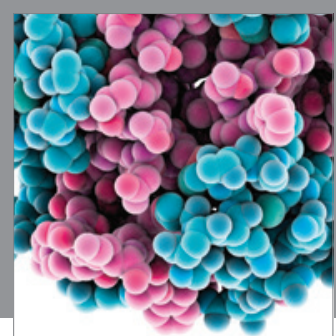

Journal of
Diabetes Research

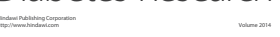

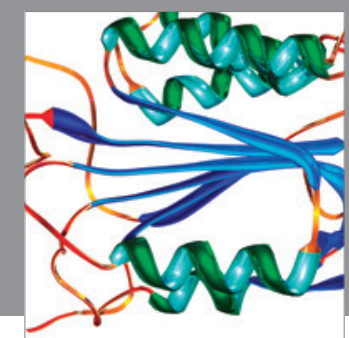

Disease Markers
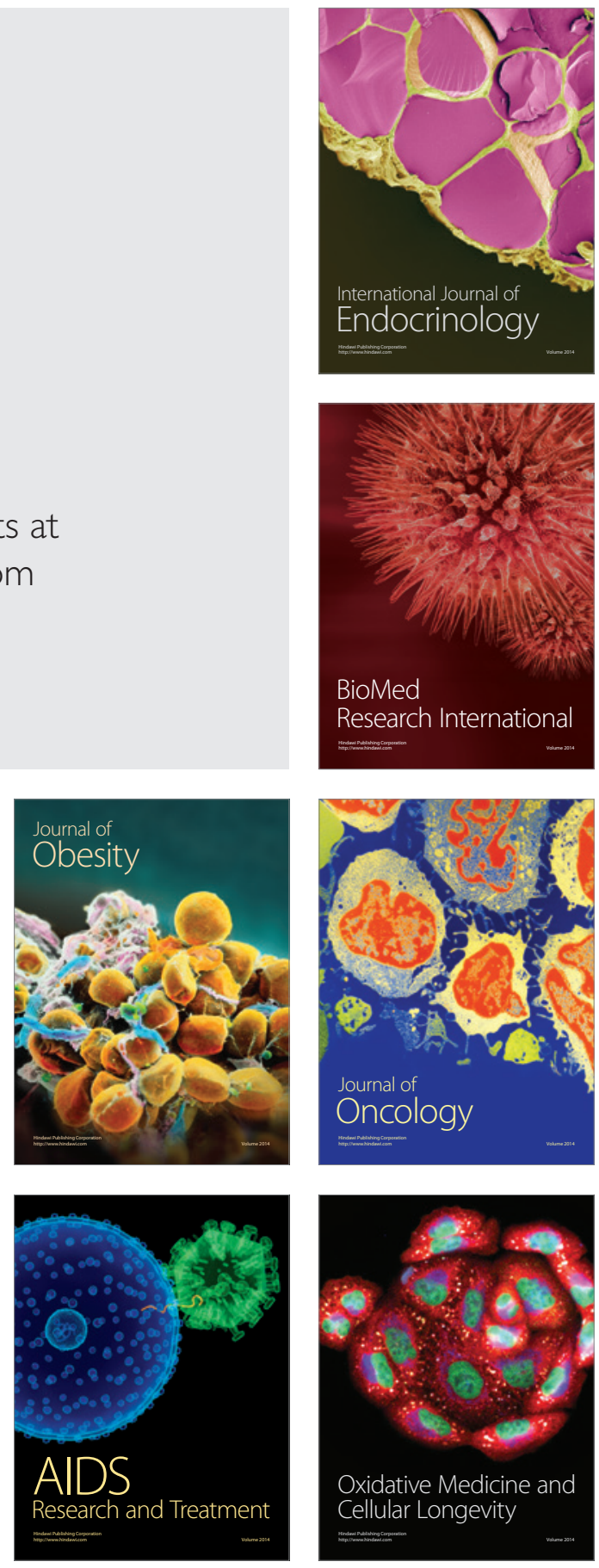